\title{
Inconsistencies In Textbook Presentation Of Capital Budgeting Criteria
}

\author{
Frank Elston, (Email: elston@cord.edu), Concordia College
}

\begin{abstract}
Corporate finance textbooks state conflicting criteria for capital budgeting projects. There are three main versions of the criteria, which contradict one another. Some texts advocate accepting all projects with a positive or zero net present value (equivalently, all projects with internal rate of return exceeding or equaling the required rate of return). Other texts call for accepting only positive NPV projects and rejecting those with zero NPVs. Still other texts advocate indifference when NPV is zero. The texts then are inconsistent with one another in a matter of straightforward theory. Moreover, a number of textbooks are internally inconsistent, stating rules for the case of $N P V$ equals zero that are at odds with their stated rule for the IRR criterion. In practical finance, the implications of this theoretical difference will be very limited. For pedagogy, however, the failure to state theory correctly and clearly can have a greater impact upon learning.
\end{abstract}

\section{INTRODUCTION}

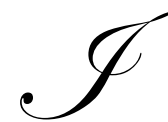

$\mathrm{t}$ is notable that among corporate finance books we can find a theoretical disagreement about capital budgeting criteria. Corporate finance textbooks state conflicting criteria for capital budgeting projects both in respect to internal rate of return (IRR) and net present value (NPV). Some texts advocate accepting all projects with a positive or zero NPV or equivalently, all projects with internal rate of return exceeding or equaling the required rate of return. Other texts call for accepting only positive NPV projects; hence, the disagreement centers on the projects with zero NPV.

The disagreements among the various textbook authors are important for theory and for pedagogy, but not for practice. In practical finance, the implications of this theoretical difference will be very limited. How often will projects produce exactly a zero NPV? For pedagogy, however, the failure to state theory correctly and clearly can have a greater impact upon learning. Moreover, the interrelationship of capital budgeting, cost of capital, and markets for securities may lead to other inconsistencies of nomenclature and meaning.

A review of journals did not disclose any articles addressing how textbooks approached capital budgeting criteria. In this paper we will survey fifteen leading texts. Related textbooks with the same authors are not included. Usually identical language appeared in the related textbooks. Interestingly, many of the surveyed texts do not address the criterion in a direct and complete way, while others state contradictory or inconsistent criteria. We will survey how authors establish NPV and IRR capital budgeting criteria. Thereafter we will explore related issues.

\section{SURVEY OF TEXTBOOKS}

\section{Acceptance Proposition}

Keown, Martin, Petty, and Scott (2003:253) indicate how to apply the NPV criterion:

Whenever the project's NPV is greater than or equal to zero, we will accept the project; whenever the NPV is negative, we will reject the project. If the project's NPV is zero, then it returns the required rate of return and should be accepted. 
Similarly, Keown et al (2003: 257) apply the IRR criterion:

The decision criterion is to accept the project if the IRR is greater than or equal to the required rate of return. We reject the project if its IRR is less than the required rate of return. . . If the IRR on a project is equal to the shareholders' required rate return, then the project should be accepted because the firm is earning the rate that its shareholders are requiring. However, the acceptance of a project with an IRR below the investors' required rate of return will decrease the firm's stock price.

We will call this the Acceptance Proposition. With this rule the decision-maker accepts projects with zero NPV or projects whose IRR equals the required return. For purposes of our discussion, we assume projects of average riskiness so that a firm's cost of capital represents the opportunity cost of the specific project. In general when a project's risk differs from the risk of the firm, we would wish to use a criterion that adjusts the cost of capital in determining the required rate of return.

Jackson (2000: 253) also endorses acceptance of zero NPV projects: "In general, the decision rules are to accept all projects with net present value greater than or equal to 0." Other textbook authors such as Block and Hirt (2000: 353) appear to endorse the Acceptance Proposition: "In both the internal rate of return and net present value methods, the profitability must equal or exceed the cost of capital for the project to be potentially acceptable." Likewise, Gallagher and Andrew (2003: 274-75) endorse the acceptance of projects with zero NPV, even acknowledging that these projects do not add value to the firm: "A firm should accept all independent projects having NPVs greater than or equal to zero. ... Projects with NPVs of zero will not alter the firm's value but (just) meet the firm's requirements."

\section{Indifference Proposition}

In contrast, Ross, Westerfield, and Jordan (2003: 276) present us with the Indifference Proposition when discussing NPV:

An investment should be accepted if the net present value is positive and rejected if it is negative. In the unlikely event that the net present value turned out to be exactly zero, we would be indifferent between taking the investment and not taking it.

The Indifference Proposition calls for the decision-maker to be indifferent for projects with zero NPV or projects whose IRR equals the cost of capital. Under this Proposition it is ok to accept or reject those projects. Oddly enough Ross et al (2003: Transparency 25.16) provide a transparency which endorses the Acceptance Proposition: "Remember that a zero-NPV investment is also desirable."

\section{Rejection Proposition}

Furthermore, when Ross et al (2003: 258) state the IRR criterion for the case of equality of IRR and the cost of capital, they recommend rejection: "Based on the IRR rule, an investment is acceptable if the IRR exceeds the required return. It should be rejected otherwise." This then is the Rejection Proposition. With this rule the decisionmaker rejects projects with a zero NPV and whose IRR equals the cost of capital.

\section{NPV - IRR Decision Inconsistencies}

In addition to Ross et al other authors are also guilty of NPV-IRR inconsistency. Van Horne and Wachowicz (2001: 338) endorse the Acceptance Proposition for the NPV in the first sentence and then restate the idea of acceptance referring only to the situation of a positive NPV: "If an investment project's net present value is zero or more, the project is accepted; if not it is rejected. Another way to express the acceptance criterion is to say that the project will be accepted if the present value of cash inflows exceeds the present value of cash outflows." However, Van Horne and Wachowicz (2001: 337) recommend rejecting projects whose IRR is equal to the cost of capital: "If the internal rate of return exceeds the required rate, the project is accepted; if not, the project is rejected." 
In addition to the inconsistency of treatment for NPV and IRR, several textbook authors do not forthrightly state whether the decision-maker should accept, reject, or be indifferent. Shapiro and Balbirer (2000) do not directly agree with the Acceptance Proposition, but appear to adopt it in the course of discussing IRR. After stating that when IRR exceeds the cost of capital, we should accept the project and reject the project when the reverse is true, Shapiro and Balbirer (2000: 249) try to clarify further the use of the IRR:

... the IRR is the interest rate that would make the NPV of a project zero. The IRR may also be interpreted as the maximum interest rate that you would be willing to pay on long-term funds in order to finance the project. For a project to be accepted under the IRR decision criterion, its IRR must exceed the required rate of return.

The second sentence above indicates that one would accept a project where IRR equals the cost of capital. This, of course, is the case of NPV equals 0. Interestingly, Shapiro and Balbirer (2000) contradict themselves immediately in the third sentence by stating the IRR decision criterion as requiring the IRR to exceed the required rate of return. Hence NPV must exceed 0 to accept a project.

Brigham and Houston (2001) and Brealey, Myers, Marcus (2001) cannot easily be assigned to any of the three propositions, as they do not indicate what the decision-maker should do in the case of a zero NPV. Brigham and Houston (2001: 506) clearly state what to do with projects with positive or negative NPVs: "If the NPV is positive, the project should be accepted, while if the NPV is negative, it should be rejected." Unfortunately, they do not state what to do with the zero NPV project. Similarly, in the case of IRR we read:

"(2) If the internal rate of return exceeds the cost of the funds used to finance the project, a surplus remains after paying for the capital, and this surplus accrues to the firm's stockholders. (3) Therefore, taking on a project whose IRR exceeds its cost of capital increases shareholders' wealth. On the other hand, if the internal rate of return is less than the cost of capital, then taking on the project imposes a cost on current stockholders." (2001: 511)

Hence at best we can infer indifference as to accepting and rejecting for the zero NPV project.

Table 1 provides a summary of textbook positions on capital budgeting criteria. It is apparent that the authors are all over the place on a matter that invites and demands precision and unity. Six or $40 \%$ of the fifteen textbooks recommend acceptance of zero NPV projects. Twenty percent of the textbooks state different propositions for the zero NPV case and the IRR equals the required rate of return case. Forty percent of the textbooks state the criteria in less than a clear manner so that the reader is left to infer the proposition. Only a minority of the textbooks, $40 \%$, provide the correct statement of indifference for the case of zero NPV. Of these six cases, three are not stated definitively and one is inconsistent with the case of IRR equals the required rate of return. In fact, only one of the fifteen text writers, Mayo, is correct and consistent. He adopts the correct proposition of indifference in regard to the case of the zero NPV, states the proposition clearly without need for inference, and advocates this proposition also for the required rate of return case.

\section{THE PROPER SOLUTION}

Sometimes theories may appear incompatible, but are not entirely so. One theory may explain phenomenon observed at a certain point of time, but not at all times. Moreover, the theory may not fully explain the phenomenon. In essence, theories may complement one another in explaining the data. An example of these situations where theories are not wholly incompatible might be theories regarding the term structure of interest rates. For example, assume a 200 basis point premium for long term rates. This premium may reflect both an expectation of rising short term rates and a reluctance to lend long.

Other times theories are mutually exclusive. The truth of one makes false the other. Are the theories regarding capital budgeting criteria incompatible? That is, is the truth of one implies that the other must be false? Clearly yes. The Acceptance Proposition and the Rejection Proposition are incompatible with one another. There is a manifest contradiction between instructing the decision-maker simultaneously to accept a project with zero NPV and 


\begin{tabular}{|l|c|c|}
\hline \multicolumn{2}{|c|}{ Table 1 - Summary Of Decision For Capital Budgeting Projects } \\
\hline \multicolumn{1}{|c|}{ Text } & NPV = 0 & IRR = Required Return \\
\hline Besley \& Brigham (2000) & Imply non acceptance & Imply non acceptance \\
\hline Block \& Hirt (2000) & Accept & Accept \\
\hline Brealey \& Myers (1996) & Imply non acceptance & Imply non acceptance \\
\hline Brealey Myers Marcus (2001) & Imply non acceptance & Imply indifference \\
\hline Brigham \& Ehrhardt (2002) & Imply indifference & Imply indifference \\
\hline Brigham \& Houston (2001) & Imply indifference \\
\hline Gallagher \& Andrew (2003) & Accept & Accept \\
\hline Hickman, Hunter, Byrd (2002) & Indifferent & Accept \\
\hline Jackson (2000) & Accept & Indifferent \\
\hline Keown Martin Petty Scott (2003) & Accept & Accept \\
\hline Mayo (2001) & Indifferent & Reject \\
\hline Moyer, McGuigan, Kretlow (2001) & Accept & Imply indifference, accept \\
\hline Ross Westerfield Jordan (2003) & Indifferent & Reject \\
\hline Shapiro \& Balbirer (2000) & Imply indifference & Accept \\
\hline Van Horne \& Wachowiz (2001) & & Accent \\
\hline
\end{tabular}

to reject such a project. For if the decision-maker decides to reject the project, there is a violation of one criterion, but not a violation of the other criterion. The instruction that a project should or must be accepted violates the Indifference Proposition. But the actual decision to accept is allowable under the Indifference Proposition, for indifference allows for accepting or rejecting. The Indifference Proposition, however, differs from the Acceptance Proposition by not mandating acceptance and differs from the Rejection Proposition by not mandating rejection.

The truth of these three Propositions is a matter of reason and not empirical testing. The best approach is to adopt the Indifference Proposition and accordingly not mandate acceptance or rejection for projects with an NPV equals 0 . These projects neither increase nor decrease value. Any rule mandating acceptance for projects that have NPV equals 0 lacks a basis in so far as value creation is the objective. To accept such a project does not increase value. No other objective appears on the horizon to justify accepting projects with zero addition to wealth.

With regard to the Rejection Proposition, the argument is somewhat more subtle and less clear cut. Any rule mandating rejection for a project that has NPV equal to 0 does not violate value creation. By applying the Rejection Proposition we do not lose out on value creating projects, nor do we fail to fund value creating projects. Hence, there is a certain logic to reject as the goal of increasing value is not achieved when NPV equals 0.

One type of error in decision making is to reject a project that is value creating, which is to say has a positive NPV. Another type of error is to accept a project with a negative NPV. Suppose our criterion is to accept projects with zero NPV. If we failed to accept such a project, this would be an error in terms of the criterion, but not an error in terms of value creation. Similarly, suppose our criterion is to reject projects with zero NPV. Failure to reject such a project would constitute an error in terms of the criterion, but not an error in terms of value creation. Suppose our criterion calls for indifference in those cases of zero NPV. Whether we accepted or rejected a zero NPV project, we would not have violated the capital budgeting criterion, nor would we have harmed the cause of value creation. Therefore, the criterion of indifference establishes a consistency between an error in terms of the criterion and an error in terms of value creation. For this reason the Indifference Proposition is preferable to the Rejection Proposition and to the Acceptance Proposition. 
There are three main characteristics of a good rule for capital budgeting when NPV equals 0 or IRR equals the required rate of return. First, a good rule is explicitly stated. The reader does not have to infer it. Second, the rule is consistent as between IRR and NPV. In that IRR is the discount rate such that NPV equals 0, a consideration of NPV and IRR should provide the same decision. Third, the rule should advocate indifference and not mandate acceptance, nor mandate rejection. While there is some logic for rejection, indifference is still preferable.

\section{Capital Budgeting Criteria, Required Return, and Pedagogy}

Incorrectly stating capital budgeting criteria has pedagogical implications. In learning finance students need clearly and consistently stated theory. Students hear about the idea of wealth creation early in the textbook only to learn several chapters later that projects adding nothing to value should be accepted. Clearly stating theory is not the same as oversimplifying the real world. Although an application may very well involve complexities dictated by uncertainty and interdependence, the criteria for capital budgeting can be stated clearly. Otherwise, financial economics loses some of its power. This power derives in part by the existence of a few consistent cardinal principles, applied rigorously. These help students to tie the material together. But muddled ideas cannot further student learning; at best they provide information. If material cannot be tied together, the material becomes assertions to be memorized. There is no valid reason for not stating clearly what the decision-maker should do. This dictum should be consistent with the goal of value maximization.

\section{CONCLUSION}

Capital budgeting criteria can be stated either in terms of NPV or IRR. The criteria can advocate acceptance, rejection, or indifference. The focus in this article is the situation where NPV equals zero or IRR equals the required return. A consistent statement would be accept when NPV equals zero and accept when the IRR equals the required return. Other consistent statements are reject and reject as well as indifferent and indifferent. This article has shown that many textbook authors do not state capital budgeting consistently. Moreover, even when consistent, many authors do not embrace the preferred solution, namely indifference.

\section{REFERENCES}

1. $\quad$ Besley, S., Brigham, E.F., (2000). Essentials of Managerial Finance, twelfth edition, Dryden.

2. Block, S.B., Hirt, G.A., (2000). Foundations of Financial Management, ninth edition, Irwin McGraw Hill.

3. Brealey, R.A., Myers, S.C., (1996). Principles of Corporate Finance, fifth edition, McGraw-Hill.

4. Brealey, R.A., Myers, S.C., Marcus, A.J., (2001). Fundamentals of Corporate Finance, third edition, Irwin McGraw-Hill.

5. Brigham, E.F., Ehrhardt, M.C., (2002). Financial Management: Theory and Practice, tenth edition, Harcourt.

6. Brigham, E.F., Houston, J.F., (2001). Fundamentals of Financial Management, ninth edition, Harcourt.

7. Gallagher, T.J., Andrew Jr., J.D., (2003). Financial Management: Principles and Practice, third edition, Prentice Hall.

8. Hickman, K.A., Hunter, H.O., Byrd, J.W., (2002). Foundations of Corporate Finance, second edition, Southwestern.

9. Jackson, K.L. (2000). Collaborative Finance, Southwestern.

10. Keown, A.J., Martin, J.D., Petty, J.W., Scott, Jr., D.F., (2003). Foundations of Finance: The Logic and Practice of Financial Management, fourth edition, Prentice Hall.

11. Mayo, H.B., (2001). Financial Institutions, Investments, and Management: An Introduction, seventh edition, Harcourt.

12. Moyer, R.C., McGuigan, J.R., Kretlow, W.J., (2001). Contemporary Financial Management, Southwestern Thomson Learning.

13. Ross, S.A., Westerfield, R.W., Jordan, B.D., (2003). Fundamentals of Corporate Finance, sixth edition, Irwin McGraw-Hill.

14. Shapiro, A.C., Balbirer, S.D., (2000). Modern Corporate Finance, Prentice Hall.

15. Van Horne, J.C., Wachowicz Jr., J.M., (2001). Fundamentals of Financial Management, eleventh edition, Prentice Hall. 


\section{NOTES}

